\title{
Distributive Justice as a Means of Combating Systemic Racism in Healthcare
}

\author{
Derek Soled*
}

ABSTRACT

COVID-19 highlighted a disproportionate impact upon marginalized communities that needs to be addressed. Specifically, a focus on equity rather than equality would better address and prevent the disparities seen in COVID-19. A distributive justice framework can provide this great benefit but will succeed only if the medical community engages in outreach, anti-racism measures, and listens to communities in need.

Keywords: Health inequity, health disparity, COVID-19, health equity, socioeconomic, marginalized

\section{INTRODUCTION}

COVID-19 disproportionately impacted communities of color and lower socioeconomic status, sparking political discussion about existing inequities in the US. ${ }^{1}$ Some states amended their guidelines for allocating resources, including vaccines, to provide care for marginalized communities experiencing these inequities, but there has been no clear consensus on which guidelines states should amend or how they should be ethically grounded. In part, this is because traditional justice theories do not acknowledge the deep-seated institutional and interpersonal discrimination embedded in our medical system. Therefore, a revamped distributive justice approach that accounts for these shortcomings is needed to guide healthcare decisionmaking now and into the post-COVID era.

\section{BACKGROUND}

Three terms - health disparity, health inequities, and health equity - help frame the issue. A health disparity is defined as any difference between populations in terms of disease incidence or adverse health events, such as morbidity or mortality. In contrast, health inequities are health disparities due to avoidable systematic structures rooted in racial, social, and economic injustice. ${ }^{2}$ For example, current data demonstrate that Black, Latino, Indigenous Americans, and those living in poverty suffer higher morbidity and mortality rates from COVID-19. ${ }^{3}$ Finally, health equity is the opportunity for anyone to attain his or her full health potential without interference from systematic structures and factors that generate health inequities, including race, socioeconomic status, gender, ethnicity, religion, sexual orientation, or geography. ${ }^{4}$

\footnotetext{
* Derek Soled, Candidate MD, MBA, Harvard University
}

(C) 2021 Derek Soled. This is an open access article distributed under the terms of the Creative Commons Attribution License, which permits unrestricted use, distribution, and reproduction, provided the original author and source are credited. 
Health inequities for people of color with COVID-19 have led to critiques of states that do not account for race in their resource allocation guidelines. ${ }^{5}$ For example, the Massachusetts Department of Public Health revised its COVID-19 guidelines regarding resource allocation to patients with the best chance of shortterm survival. ${ }^{6}$ Critics have argued that this change addresses neither preexisting structural inequities nor provider bias that may have led to comorbidities and increased vulnerability to COVID-19. By failing to address race specifically, they argue the policy will perpetuate poorer outcomes in already marginalized groups. As the inequities in COVID-19 outcomes continue to be uncovered and the data continue to prove that marginalized communities suffered disproportionately, we, as healthcare providers, must reconsider our role in addressing the injustices. Our actions must be ethically grounded in the concept of justice.

I. Primary Theories of Justice

The principle of justice in medical ethics relates to how we ought to treat people and allocate resources. Multiple theories have emerged to explain how justice should be implemented, with three of the most prominent being egalitarianism, utilitarianism, and distributive. This paper argues that distributive justice is the best framework for remedying past actions and enacting systemic changes that may persistently prevent injustices.

An egalitarian approach to justice states all individuals are equal and, therefore, should have identical access to resources. In the allocation of resources, an egalitarian approach would support a strict distribution of equal value regardless of one's attributes or characteristics. Putting this theory into practice would place a premium on guidelines based upon first-come, first-served basis or random selection. ${ }^{7}$ However, the egalitarian approach taken in the UK continues to worsen health inequities due to institutional and structural discrimination. ${ }^{8}$

A utilitarian approach to justice emphasizes maximizing overall benefits and achieving the greatest good for the greatest number of people. When resources are limited, the utilitarian principle historically guides decision making. In contrast to the egalitarian focus on equal distribution, utilitarianism focuses on managing distributions to maximize numerical outcomes. During the COVID-19 pandemic, guidelines for allocating resources had utilitarian goals like saving the most lives, which may prioritize the youthful and those deemed productive in society, followed by the elderly and the very ill. It is important to reconsider using utilitarian approaches as the default in the post-COVID healthcare community. These approaches fail to address past inequity, sacrificing the marginalized in their emphasis on the greatest amount of good rather than the type of good.

Finally, a distributive approach to justice mandates resources should be allocated in a manner that does not infringe individual liberties to those with the greatest need. Proposed by John Rawls in a Theory of Justice, this approach requires accounting for societal inequality, a factor absent from egalitarianism and utilitarianism. ${ }^{9}$ Naomi Zack elaborates how distributive justice can be applied to healthcare, outlining why racism is a social determinant of health that must be acknowledged and addressed. ${ }^{10}$

Until there are parallel health opportunities and better alignment of outcomes among different social and racial groups, the underlying systemic social and economic variables that are driving the disparities must be fixed. As a society and as healthcare providers, we should be striving to address the factors that perpetuate health inequities. While genetics and other variables influence health, the data show proportionately more exposure, more cases, and more deaths in the Black American and Hispanic 
populations. Preexisting conditions and general health disparities are signs of health inequity that increased vulnerability. Distributive justice as a theoretical and applied framework can be applied to preventable conditions that increase vulnerability and can justify systemic changes to prevent further bias in the medical community.

During a pandemic, egalitarian and utilitarian approaches to justice are prioritized by policymakers and health systems. Yet, as COVID-19 has demonstrated, they further perpetuate the death and morbidity of populations that face discrimination. These outcomes are due to policies and guidelines that overall benefit white communities over communities of color. Historically, US policy that looks to distribute resources equally (focusing on equal access instead of outcomes), in a color-blind manner, has further perpetuated poor outcomes for marginalized communities. ${ }^{11}$

\section{Historical and Ongoing Disparities}

Across socio-demographic groups, the medical system exacerbates historical and current inequities. Members of marginalized races, ${ }^{12}$ women, ${ }^{13}$ LGBTQ people, ${ }^{14}$ and poor people ${ }^{15}$ experience trauma caused by discrimination, marginalization, and failure to access high-quality public and private goods. Through the unequal treatment of marginalized communities, these historic traumas continue.

In the US, people of color do not receive equal and fair medical treatment. A meta-analysis found that Hispanics and Black Americans were significantly undertreated for pain compared to their white counterparts over the last 20 years. ${ }^{16}$ This is partly due to provider bias. Through interviewing medical trainees, a study by the National Academy of Science found that half of medical students and residents harbored racist beliefs such as "Black people's nerve endings are less sensitive than white people's" or "Black people's skin is thicker than white people's skin." ${ }^{17}$ More than 3,000 Indigenous American women were coerced, threatened, and deliberately misinformed to ensure cooperation in forced sterilization. ${ }^{18}$ Hispanic people have less support in seeking medical care, in receiving culturally appropriate care, and they suffer from the medical community's lack of resources to address language barriers. ${ }^{19}$

In the US, patients of different sexes do not receive the same quality of healthcare. Despite having greater health needs, middle-aged and older women are more likely to have fewer hospital stays and fewer physician visits compared to men of similar demographics and health risk profiles. ${ }^{20}$ In the field of critical care, women are less likely to be admitted to the ICU, less likely to receive interventions such as mechanical ventilation, and more likely to die compared to their male ICU counterparts. ${ }^{21}$

In the US, patients of different socioeconomic status do not receive the same quality of healthcare. Lowincome patients are more likely to have higher rates of infant mortality, chronic disease, and a shorter life span. ${ }^{22}$ This is partly due to the insurance-based discrimination in the medical community. ${ }^{23}$ One in three deaths of those experiencing homelessness could have been prevented by timely and effective medical care. An individual experiencing homelessness has a life expectancy that is decades shorter than that of the average American. ${ }^{24}$

\section{Action Needed: Policy Reform}

While steps need to be taken to provide equitable care in the current pandemic, including the allocation of vaccines, they may not address the historical failures of health policy, hospital policy, and clinical care to eliminate bias and ensure equal treatment of patients. According to an applied distributive justice framework, inequities must be corrected. 
Rather than focusing primarily on fair resource allocation, medicine must be actively anti-racist, anti-sexist, anti-transphobic, and anti-discriminatory. Evidence has shown that the health inequities caused by COVID19 are smaller in regions that have addressed racial wealth gaps through forms of reparations. ${ }^{25}$ Distributive justice calls for making up for the past using tools of allocation as well as tools to remedy persistent problems.

For example, Brigham and Women's Hospital in Boston, MA, began "Healing ARC," a pilot initiative that involves acknowledgement, redress, and closure on an institutional level. ${ }^{26}$ Acknowledgement entails informing patients about disparities at the hospital, claiming responsibility, and incorporating community ideas for redress. Redress involves a preferential admission option for Black and Hispanic patients to specialty services, especially cardiovascular services, rather than general medicine. Closure requires that community and patient stakeholders work together to ensure that a new system is in place that will continue to prioritize equity.

Of note, redress could take the form of cash transfers, discounted or free care, taxes on nonprofit hospitals that exclude patients of color, ${ }^{27}$ or race-explicit protocol changes (such as those being instituted by Brigham and Women's Hospital that admit patients historically denied access to certain forms of medical care). In New York, for instance, the New York State Bar Association drafted the COVID-19 resolutions to ensure that emergency regulations and guidelines do not discriminate against communities of color, and even mandate that diverse patient populations be included in clinical trials. ${ }^{28}$

Also, physicians must listen to individuals from marginalized communities to identify needs and ensure that community members take part in decision-making. The solution is not to simply build new health centers in communities of color, as this may lead to tiers of care. Rather, local communities should have a chance to impact existing hospital policy and should also use their political participation to further their healthcare interests.

Distributive justice does not seek to disenfranchise groups that hold power in the system. It aims to transform the system so that those in power do not continue to obtain unfair benefits at the expense of others. The framework accounts for unjust historical oppression and current injustices in our system to provide equitable outcomes to all who access the system. In this vein, we can begin to address the flagrant disparities between communities that have always - and continue to - exist in healthcare today. ${ }^{29}$

\section{CONCLUSION}

As equality focuses on access, it currently fails to do justice. Instead of outcomes, it is time to focus on equity. A focus on equity rather than equality would better address and prevent the disparities seen in COVID-19. A distributive justice framework can gain traction in clinical decision-making guidelines and system-level reallocation of resources but will succeed only if the medical community engages in outreach, anti-racism measures, and listens to communities in need. There should be an emphasis on implementing a distributive justice framework that treats all patients equitably, accounts for historical harm, and focuses on transparency in allocation and public health decision making.

\footnotetext{
${ }^{1}$ APM Research Lab Staff. 2020. "The Color of Coronavirus: COVID-19 Deaths by Race and Ethnicity in the U.S." APM Research Lab. https://www.apmresearchlab.org/covid/deaths-by-race.

2 Bharmal, N., K. P. Derose, M. Felician, and M. M. Weden. 2015. "Understanding the Upstream Social Determinants of Health." California: RAND Corporation 1-18. https://www.rand.org/pubs/working_papers/WR1096.html.
} 
${ }^{3}$ Yancy, C. W. 2020. "COVID-19 and African Americans." JAMA. 323 (19): 1891-2. https://doi.org/10.1001/jama.2020.6548; Centers for Disease Control and Prevention. 2020. "COVID-19 in Racial and Ethnic Health Disparities." Centers for Disease Control and Prevention. https://www.cdc.gov/coronavirus/2019-ncov/community/health-equity/racial-ethnic-disparities/index.html.

${ }^{4}$ Braveman, P., E. Arkin, T. Orleans, D. Proctor, and A. Plough. 2017. "What is Health Equity?" Robert Wood Johnson Foundation. https://www.rwjf.org/en/library/research/2017/05/what-is-health-equity-.html.

${ }^{5}$ Bedinger, M. 2020 Apr 22. "After Uproar, Mass. Revises Guidelines on Who Gets an ICU Bed or Ventilator Amid COVID-19 Surge." Wbur. https://www.wbur.org/commonhealth/2020/04/20/mass-guidelines-ventilator-covid-coronavirus; Wigglesworth, A. 2020 May 11. "Institutional Racism, Inequity Fuel High Minority Death Toll from Coronavirus, L.A. Officials Say." Los Angeles Times. https://www.latimes.com/california/story/2020-05-11/institutional-racism-inequity-high-minority-death-toll-coronavirus.

${ }^{6}$ Executive Office of Health and Human Services Department of Public Health. 2020 Oct 20. "Crises Standards of Care Planning and Guidance for the COVID-19 Pandemic." Commonwealth of Massachusetts. https://www.mass.gov/doc/crisis-standards-ofcare-planning-guidance-for-the-covid-19-pandemic.

${ }^{7}$ Emanuel, E. J., G. Persad, R. Upshur, et al. 2020. "Fair Allocation of Scarce Medical Resources in the Time of Covid-19. New England Journal of Medicine 382: 2049-55. https://doi.org/10.1056/NEJMsb2005114.

8 Salway, S., G. Mir, D. Turner, G. T. Ellison, L. Carter, and K. Gerrish. 2016. "Obstacles to "Race Equality" in the English National Health Service: Insights from the Healthcare Commissioning Arena." Social Science and Medicine 152: 102-110.

https://doi.org/10.1016/j.socscimed.2016.01.031.

${ }^{9}$ Rawls, J. A Theory of Justice (Revised Edition) (Cambridge, MA: Belknap Press of Harvard University Press, 1999).

10 Zack, N. Applicative Justice: A Pragmatic Empirical Approach to Racial Injustice (New York: The Rowman \& Littlefield Publishing Group, 2016).

${ }^{11}$ Charatz-Litt, C. 1992. "A Chronicle of Racism: The Effects of the White Medical Community on Black Health." Journal of the National Medical Association 84 (8): 717-25. http://hdl.handle.net/10822/857182.

12 Washington, H. A. Medical Apartheid: The Dark History of Medical Experimentation on Black Americans from Colonial Times to the Present (New York: Doubleday, 2006).

${ }^{13}$ d'Oliveira, A. F., S. G. Diniz, and L. B. Schraiber. 2002. "Violence Against Women in Health-care Institutions: An Emerging Problem." Lancet. 359 (9318): 1681-5. https://doi.org/10.1016/S0140-6736(02)08592-6.

14 Hafeez, H., M. Zeshan, M. A. Tahir, N. Jahan, and S. Naveed. 2017. “Health Care Disparities Among Lesbian, Gay, Bisexual, and Transgender Youth: A Literature Review. Cureus 9 (4): e1184. https://doi.org/10.7759/cureus.1184; Drescher, J., A. Schwartz, F. Casoy, et al. 2016. "The Growing Regulation of Conversion Therapy." Journal of Medical Regulation 102 (2): 7-12. https://doi.org/10.30770/2572-1852-102.2.7; Stroumsa, D. 2014. "The State of Transgender Health Care: Policy, Law, and Medical Frameworks." American Journal of Public Health. 104 (3): e31-8. https://doi.org/10.2105/AJPH.2013.301789.

${ }^{15}$ Stepanikova, I., and G. R. Oates. 2017. "Perceived Discrimination and Privilege in Health Care: The Role of Socioeconomic Status and Race." American Journal of Preventative Medicine. 52 (1s1): S86-s94. https://doi.org/10.1016/j.amepre.2016.09.024; Swartz, K. "Health Care for the Poor: For Whom, What Care, and Whose Responsibility?" In Cancian, M., and S. Danziger (Eds.). Changing Poverty, Changing Policies (New York: Russell Sage Foundation Press, 2009), 69-74.

16 Meghani, S. H., E. Byun, and R. M. Gallagher. 2012. "Time to Take Stock: A Meta-analysis and Systematic Review of Analgesic Treatment Disparities for Pain in the United States." Pain Medicine 13 (2): 150-74. https://doi.org/10.1111/i.15264637.2011.01310.x; Williams, D. R., and T. D. Rucker. 2000. "Understanding and Addressing Racial Disparities in Health Care." Health Care Financing Review 21 (4): 75-90. https://scholar.harvard.edu/davidrwilliams/dwilliam/publications/understandingand-addressing-racial-disparities-health.

17 Hoffman, K. M., S. Trawalter, J. R. Axt, and M. N. Oliver. 2016. "Racial Bias in Pain assessment and treatment recommendations, and false beliefs about biological Differences Between Blacks and Whites." PNAS 113 (16): $4296-4301$. https://doi.org/10.1073/pnas.1516047113. 
18 Pacheco, C. M., S. M. Daley, T. Brown, M. Filipp, K. A. Greiner, and C. M. Daley. 2013. "Moving Forward: Breaking the Cycle of Mistrust Between American Indians and Researchers." American Journal of Public Health. 103 (12): 2152-9. https://doi.org/10.2105/AJPH.2013.301480.

19 Velasco-Mondragon, E., A. Jimenez, A. G. Palladino-Davis, D. Davis, and J. A. Escamilla-Cejudo. 2016. "Hispanic Health in the USA: A Scoping Review of the Literature." Public Health Reviews 37:31. https://doi.org/10.1186/s40985-016-0043-2.

${ }^{20}$ Cameron, K. A., J. Song, L. M. Manheim, and D. D. Dunlop. 2010. "Gender Disparities in Health and Healthcare Use Among Older Adults." Journal of Women's Health (Larchmt) 19 (9): 1643-50. https://doi.org/10.1089/jwh.2009.1701.

${ }^{21}$ Bierman, A. S. 2007. "Sex Matters: Gender Disparities in Quality and Outcomes of Care. Canadian Medical Association Journal 177 (12): 1520-1. https://doi.org/10.1503/cmaj.071541; Fowler, R. A., S. Sabur, P. Li, et al. 2007. "Sex-and Age-based Differences in the Delivery and Outcomes of Critical Care. Canadian Medical Association Journal 177 (12): 1513-9. https://doi.org/10.1503/cmaj.071112.

22 McLaughlin, D. K., and C. S. Stokes. 2002. "Income Inequality and Mortality in US Counties: Does Minority Racial Concentration Matter?" American Journal of Public Health 92 (1): 99-104. https://doi.org/.10.2105/ajph.92.1.99; Shea, S., J. Lima, A. Diez-Roux, N. W. Jorgensen, and R. L. McClelland. 2016. "Socioeconomic Status and Poor Health Outcome at 10 years of Follow-up in the Multi-ethnic Study of Atherosclerosis." PLoS One 11 (11): e0165651. https://doi.org/10.1371/journal.pone.0165651.

${ }^{23}$ Han, X., K. T. Call, J. K. Pintor, G. Alarcon-Espinoza, and A. B. Simon. 2015. "Reports of Insurance-based Discrimination in Health care and its Association with Access to Care." American Journal of Public Health 105 Suppl 3 (Suppl 3): S517-25. https://doi.org/10.2105/AJPH.2015.302668.

${ }^{24}$ Aldridge, R. W., D. Menezes, D. Lewer, et al. 2019. "Causes of Death Among Homeless People: A Population-based Crosssectional Study of Linked Hospitalization and Mortality Data in England." Wellcome Open Research 4:49.

https://doi.org/10.12688/wellcomeopenres.15151.1.

25 Richardson, E. T., M. M. Malik, W. A. Darity Jr., et al. 2021. "Reparations for Black American Descendants of Persons Enslaved in the U.S. and their Potential Impact on SARS-CoV-2 Transmission." Social Science and Medicine 276: 113741. https://doi.org/10.1016/i.socscimed.2021.113741.

${ }^{26}$ Wispelwey, B., and M. Morse. 2021. "An Antiracist Agenda for Medicine." Boston Review. http://bostonreview.net/sciencenature-race/bram-wispelwey-michelle-morse-antiracist-agenda-medicine.

27 Johnson, S. F., A. Ojo, and H. J. Warraich. 2021. "Academic Health Centers' Antiracism Strategies Must Extend to their Business Practices." Annals of Internal Medicine 174 (2): 254-5. https://doi.org/10.7326/M20-6203; Golub, M., N. Calman, C. Ruddock, et al. 2011. "A Community Mobilizes to End Medical Apartheid." Progress in Community Health Partnerships: Research, Education, and Action 5 (3): 317-25. https://doi.org/10.1353/cpr.2011.0041.

${ }^{28}$ New York State Bar Association. 2020. "New York State Bar Association House of Delegates: Revised COVID-19 Resolutions." https://nysba.org/app/uploads/2020/10/Final-Health-Law-Section-COVID-19-Resolutions_10-8-20-1-1.pdf.

29 Egede, L. E. 2006. "Race, Ethnicity, Culture, and Disparities in Health Care." Journal of General Internal Medicine 21 (6): 667669. https://doi.org/10.1111\%2Fj.1525-1497.2006.0512.x 